\title{
Las ciencias sociales como discurso de la salud reproductiva. El ejemplo del climaterio femenino
}

The social sciences as discourse in reproductive health. The example of female climacteric

1 Clínica Psiquiátrica Universitaria, Facultad de Medicina, Universidad de Chile. Av. La Paz 1003, Casilla 70010, Santiago, Chile. flolas@abello.dic.uchile.cl

\begin{abstract}
Climacteric is constructed by medicine, lay knowledge, and the social sciences. This article examines the interrational models involving these different discourses and proposes that the contribution of the social sciences lies in a reformulation of the cognitive base of the health professions at an integrative level.

Key words Social Sciences; Medicine; Reproductive Health; Climacteric

Resumen Tomando como ejemplo la construcción del climaterio femenino por parte de la medicina, de la opinión profana y de las ciencias sociales, se examinan los modelos de interrelación entre estos discursos y se propone la tesis de que la aportación de las ciencias sociales consiste en una reformulación de la base cognitiva de las profesiones de la salud en un nivel de integración. Palabras clave Ciencias Sociales; Medicina; Salud Reproductiva; Climaterio
\end{abstract}




\section{El discurso científico y la biografía}

Como otros ámbitos de la vida humana, el vinculado a la reproducción está sujeto a permanentes transiciones. Desde el punto de vista biológico, como asimismo desde las perspectivas cultural y social, existen períodos de cambio más acelerado en los que la transición adopta el carácter de crisis y adquiere una radicalidad que la convierte en posibilidad de crecimiento o retroceso, oportunidad y amenaza. Casi todas las culturas aceptan la existencia de "crisis normales" al alcanzar la madurez sexual, al ser padre o madre y al perder la capacidad reproductiva.

Lo significativo de tales crisis es que no son solamente cambios biológicos, aunque estos constituyan su fundamento. Su real significación radica en su carácter biográfico, que permite interpretarlos como positivos y negativos.

La tesis central de este artículo es que los temas del sentido y significación del cambio biológico-biográfico que supone toda crisis deben ser abordados desde una perspectiva integradora. Naturalmente, una postura científica no puede referirse a una vaga generalidad y se concreta en disciplinas parciales y específicas, con contenidos, audiencias y métodos propios. La relación entre disciplinas no puede disociarse de las formas de socialización profesional que cada grupo de expertos impone a sus miembros y del poder social que estos alcanzan.

En el campo de la salud, esta relación interdisciplinaria adquiere contornos específicos. La medicina clínica y la salud pública fueron reformuladas profundamente en el siglo XIX, bajo la influencia del paradigma científico-natural de corte positivista. Los éxitos de las ciencias fundamentales y el establecimiento de una racionalidad privilegiada por los centros de decisión política y económica llevaron a tipificar lo "científico" como una forma excluyente de abordar algunas realidades, sin la cual eran posibles sólo opiniones y no certidumbres. Ha de advertirse que ello no guarda relación con el contenido de verdad ni con la pureza de los métodos, sino, esencialmente, con el carácter encrático, corporizador del poder, del discurso de las disciplinas llamadas científicas. En los márgenes y en los intersticios de los saberes establecidos se incuban permanentemente discursos acráticos, que desafían al poder y la ortodoxia. Son para-dóxicos hasta que se convierten, a su vez, en ortodoxia, o modo aceptado de aludir a experiencias constitutivas de realidad.

Una disciplina, hemos indicado en otros lugares, es un discurso que crea sus propios ob- jetos (Lolas, 1992). Al hacerlo, los convierte en transmitibles, esto es, enseñables. Una disciplina es un discurso que se enseña porque sus cultores concuerdan en asignar un estatuto privilegiado a los objetos de que hablan, los cuales existen en virtud de ese "ser mentados" con significación. Un "objeto” del discurso es algo que puede ser mentado, esto es, entrar en relaciones sujeto-predicado de aseveraciones apodícticas o empíricas (Lolas, 1994).

\section{El climaterio femenino como ejemplo}

Un ejemplo apropiado para examinar las antinomias de los discursos y su evolución es el climaterio femenino.

Se trata de un proceso biográfico construido por la opinión vulgar, por las tradiciones populares, por las disciplinas biológicas y por las ciencias sociales. Las diferentes formas de su construcción se evidencian en las "intervenciones” que propician. Resignación a los dictámenes de la naturaleza, superación de las barreras culturales y generacionales, alivio de los "síntomas" de la transición, evitación de las consecuencias de las alteraciones hormonales. Cada intervención supone una interpretación y anticipa un resultado.

Cuando se examina la construcción social del objeto científico "climaterio" se encuentran algunos caracteres definitorios. Se trata, en primer lugar, de un decaimiento de la función reproductiva y de la hedónica sexual. Su connotación, aún en los textos técnicos, es negativa. Su carácter de transición biográfica crítica pero esperable se ve reducido por la terminología que habla de "síntomas" del climaterio, como si fuera una enfermedad. La construcción "médica" lleva a suponer que la "condición" debe ser "tratada”, lo cual implica intervención. Como hay "síntomas", estos deben tener "causa” y las frecuentemente mencionadas se agrupan en tres grandes categorías: a) la reducción de estrógenos; b) factores socioculturales; c) factores de personalidad. Es evidente que el "peso etiológico" de cada causa difiere según el modelo. Si se sostiene que la reducción de estrógenos es más fundamental que los otros factores, los síntomas atribuíbles a ella son más substantivos y exigen corrección. Las otras causas pueden considerarse derivadas en un doble sentido: como accesorias y complementarias y como producto, o resultado, de la modificación de la tasa de estrógenos contextualizada en una cultura y una personalidad determinadas. Si se considera primaria la causa sociocultural, se podría formular la hipótesis de 
que el cambio fisiológico (reducción de estrógenos) consecuencia de ella y por ende derivado. También cabe la posibilidad de atribuir un peso etiológico igual y complementario a los factores hormonales y socioculturales.

Aunque estas tres posibilidades debieran ser dignas de examen empírico, sólo una es tomada realmente en serio: lo psicosocial se relega al papel de factor coadyuvante o secundario o, de considerarselo, no se diseña adecuados procedimientos para explicitarlo y deducir de esa explicitación medidas científicamente fundamentadas. A la inversa, el combativo "antimedicalismo" de algunos movimientos feministo-ecologistas, al subvertir el razonamiento científico-natural de la medicina académica y oponerse a cualquiera de sus fundamentos y predicciones, tiende a enjuiciar negativamente la intervención hormonal o médica. Es evidente que existen diversas formas de valorar la racionalidad empírica y minimizar la intervención del factor subjetivo, considerado insuficiente base para la toma de decisiones. No hay por ende planos equiparables, y el resultado suele ser una intervención considerada exitosa por quienes la administran pero percibida insuficiente por usuarios y público. El socavamiento de la autoridad de algunas profesiones, entre ellas la médica, deriva de subestimar nuevos puntos de vista sobre sus prácticas, o demandas que la profesión desatiende. El "lenguaje de oferta” se mueve en un plano distinto del "lenguaje de demanda”. Esto significa que las necesidades de los usuarios a veces son inadecuadamente traducidas a demandas o que la respuesta del sistema profesional atiende a sus propios criterios sin tomar en cuenta lo que los usuarios precisan.

La contradicción no puede ser resuelta en los planos de sus formulaciones originarias. A veces, ni el usuario sabe qué necesita ni el experto define adecuadamente su servicio. La necesidad de un campo intermedio, nocional y práctico, ha venido hacerse fundamental. Ese campo intermedio, en el que realmente acontece la praxis comunicativa, permite "traducir" necesidades en demandas y "saber" en "hacer". Una demanda es una necesidad que tiene sentido para el sistema experto y una respuesta de éste que la solventa no es el "saber" mismo ni un 'puro "hacer" algo, sino un "saber-hacer". La clave de una profesión exitosa en el campo social es que solvente o de respuesta a necesidades reales que se convierten en demandas legítimas. Su acción es una acción informada por teorías que permiten "dar razón” de ella y justificarla. La simple expresión de una necesidad ni la pura disposición de un saber asegu- ran que lleven al bienestar y la satisfacción de las personas. Lo que se precisa es convertir la necesidad en demanda y el saber en praxis (saber-hacer). Esto equivale a la articulación disciplinaria de un interés, del interés social que hace que las personas se vinculen, se apoyen, se ayuden, se odien y se quieran. Es ese interés el que engendra el conocimiento que no sólo se necesita sino también se demanda y que no sólo se nutre de sí mismo sino se renueva a tenor de las relaciones sociales.

Digamoslo simplemente: el ámbito de lo transdisciplinario acomoda, articula y da significado a esas construcciones sociales que son las disciplinas, las creencias, las ideologías, las expectativas y los valores. Cada uno de estos decantados de vivencias, experiencia y percepción conduce a comportamientos, genera movimiento social, produce placer o displacer, une o desune. Tiene por tanto valor performativo, "hace" algo o "hace que se hagan" cosas. Suponer que la importancia de una certeza depende de su origen ha sido el "pecado epistemocrático" de la edad técnica. No son menos eficaces las creencias populares que las conclusiones científicas en el plano del comportamiento de las personas. Bien se aprecia ello al estudiar los resultados de la educación sanitaria o al considerar el tipo de síntomas que las personas privilegian cuando consultan distintos especialistas. En el caso del climaterio femenino, no escasa proporción de los síntomas informados puede considerarse una "profecía autocumplida" respecto de lo que una mujer "tipo" debe sentir en la sociedad occidental o bien un resultado de las expectativas en relación a los sistemas de cuidado de la salud disponibles (Defey et al., 1996).

Es razonable pensar que cualquier información recogida en el ámbito sanitario está sujeta un efecto de inducción de sesgo (bias-inducing effect) por el contexto en que se genera y recolecta. Sin embargo, ello no mejora al realizar estudios "en la comunidad" si el contexto de interpretación de los datos sigue siendo el mismo. Muchas veces se considera la concordancia entre datos comunitarios y clínicos prueba de solidez de una afirmación. En realidad, a menudo se trata sólo de redundancia de la interpretación.

Descreer de todo ha sido la esperable reacción nihilizante de la postmodernidad. En algún punto, la racionalidad instrumental se atempera por la praxis comunicativa y se reconoce que la integración de saberes, de haceres y de estares permite las certezas que ayudan a vivir bien. 


\section{El papel estructurador de las ciencias sociales}

Las evidencias empíricas señalan diversos antecedentes para la sintomatología del climaterio. Algunos son relativamente esperables.

La salud previa, emocional y física, es uno de ellos. Las personas que previamente han experimentado transiciones se encuentran mejor preparadas para afrontar el cambio climatérico. También se ha señalado la experiencia previa de situaciones de extrema tensión y demanda, como asimismo separaciones. Alguna relación se ha evidenciado entre aspectos socioeconómicos y familiares y severidad de la sintomatología (Bernhard \& Shappard, apud Defey et al., 1996).

Las expectativas respecto de la propia vida, que suelen constituir una constante cultural, son un gran modificador de la forma de comunicar síntomas e incluso de la rotulación como síntoma de percepciones corporales diversas. La maternidad juega un papel importante en muchas culturas, de modo que la ausencia de embarazos para una mujer climatérica puede significar sentimientos de insuficiencia vital, frustración y duelo. La ausencia de menstruación ha sido diversamente considerada en distintos contextos, y su valoración, positiva o negativa, está influída por la percepción de los otros significativos. Esto quiere decir que en la configuración de un "hecho" personal influye la opinión que otros tengan de quien lo experimenta.

El papel estructurador de las ciencias sociales debe verse en su capacidad de constituir un conocimiento de segundo nivel. Integra la opinión experta de la medicina, la opinión experta de otros profesionales y la opinión profana de usuarios y espectadores. Cada una de estas opiniones - o posiciones, o puntos de vista constituye un espacio semántico, un espacio de significaciones. La armonía entre los distintos espacios no está dada sino debe construirse. Lo que se llama salud no es un espacio más sino un modo o forma de constituir espacios, esto es, un conocimiento de conocimientos que sólo puede lograrse constituyendo un nivel superior de integración (Lolas, 1995).

En el caso que sirve de ejemplo a la tesis, el climaterio femenino, la construcción puramento iatrotécnica de la transición biográfica es insuficiente. Lo es por la definición unilateral del padecimiento. También, por propiciar un conjunto de medidas terapéuticas que, aunque etiológicamente orientadas, no son siempre apreciadas por las destinatarias, aparte del hecho de que inducen efectos laterales perjudiciales, muchos de los cuales aguardan aún suficiente base estadística para constituir preocupación.

\section{La base cognitiva de las profesiones}

Un corolario de lo que se ha formulado es la necesidad de preparar a los profesionales de la salud en materias relacionadas con la construcción social de los hechos con que trabajan. El climaterio femenino, como toda transición vital, es más biografía que biología y debe ser entendido en forma integral. Ello implica familiaridad con los métodos y prácticas de las ciencias sociales que, sin negar ni atenuar la contribución de la biomedicina, puede incorporarse al arsenal conceptual y metódico con gran beneficio para profesionales y gente común. Esto significa ensanchar la base cognitiva de las profesiones de la salud, lo que debiera reflejarse en las materias y temas de su formación.

\section{Referencias}

DEFEY, D.; STORCH, E.; CARDOZO, S.; DIAZ, O. \& FERNANDEZ, G. 1996. The menopause: women's psychology and health care. Social Science and Medicine, 42:1447-1456.

LOLAS, F., 1992. Proposiciones para una Teoría de la Medicina. Santiago de Chile: Editorial Universitaria.

LOLAS, F., 1994. Apuntes para una ética del saber. Anuario de Filosofía Jurídica y Social, 12:99-109.

LOLAS, F., 1995. Ensayos sobre Ciencia y Sociedad. Buenos Aires: Estudio Sigma-Editorial El Ateneo. 